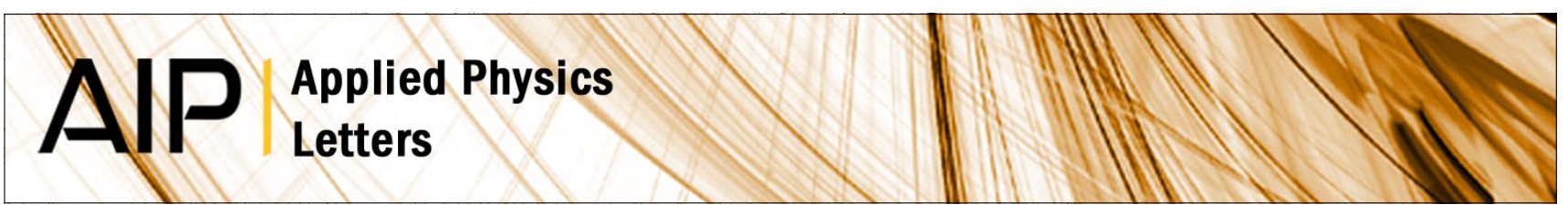

\title{
Dye-sensitized solar cell with a titanium-oxide-modified carbon nanotube transparent electrode
}

\author{
A. K. K. Kyaw, H. Tantang, T. Wu, L. Ke, C. Peh et al.
}

Citation: Appl. Phys. Lett. 99, 021107 (2011); doi: 10.1063/1.3610488

View online: http://dx.doi.org/10.1063/1.3610488

View Table of Contents: http://apl.aip.org/resource/1/APPLAB/v99/i2

Published by the American Institute of Physics.

\section{Related Articles}

Towards the development of a virtual organic solar cell: An experimental and dynamic Monte Carlo study of the role of charge blocking layers and active layer thickness

Appl. Phys. Lett. 101, 193306 (2012)

Towards the development of a virtual organic solar cell: An experimental and dynamic Monte Carlo study of the role of charge blocking layers and active layer thickness

APL: Org. Electron. Photonics 5, 246 (2012)

Towards an understanding of light activation processes in titanium oxide based inverted organic solar cells J. Appl. Phys. 112, 094503 (2012)

Highly efficient indium tin oxide-free organic photovoltaics using inkjet-printed silver nanoparticle current collecting grids

Appl. Phys. Lett. 101, 193302 (2012)

Highly efficient indium tin oxide-free organic photovoltaics using inkjet-printed silver nanoparticle current collecting grids

APL: Org. Electron. Photonics 5, 242 (2012)

\section{Additional information on Appl. Phys. Lett.}

Journal Homepage: http://apl.aip.org/

Journal Information: http://apl.aip.org/about/about_the_journal

Top downloads: http://apl.aip.org/features/most_downloaded

Information for Authors: http://apl.aip.org/authors

\section{ADVERTISEMENT}

\section{AIP Applied Physics Letters}

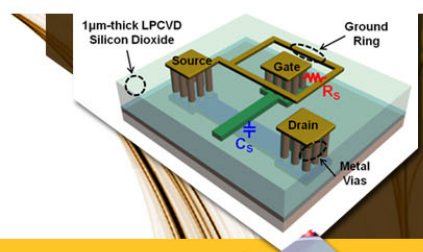

\section{SURFACES AND} INTERFACES

Focusing on physical, chemical, biological structural, optical, magnetic and electrical properties of surfaces and interfaces, and more..

\section{EXPLORE WHAT'S NEW IN APL}

SUBMIT YOUR PAPER NOW!
ENERCY CONVERSION AND STORACE 


\title{
Dye-sensitized solar cell with a titanium-oxide-modified carbon nanotube transparent electrode
}

\author{
A. K. K. Kyaw ${ }^{1,2}$ H. Tantang, ${ }^{3}$ T. Wu,${ }^{2}$ L. Ke,${ }^{4}$ C. Peh, ${ }^{4}$ Z. H. Huang, ${ }^{5}$ X. T. Zeng, ${ }^{5}$ \\ H. V. Demir, ${ }^{1,2,6}$ Q. Zhang, ${ }^{3, a)}$ and X. W. Sun ${ }^{1,7, b)}$ \\ ${ }^{1}$ School of Electrical and Electronic Engineering, Nanyang Technological University, Singapore 639798, \\ Singapore \\ ${ }^{2}$ School of Physical and Mathematical Science, Nanyang Technological University, Singapore 637371, \\ Singapore \\ ${ }^{3}$ School of Material Science and Engineering, Nanyang Technological University, Singapore 639798, \\ Singapore \\ ${ }^{4}$ Institute of Materials Research and Engineering, A*STAR (Agency for Science, Technology and Research), \\ Singapore 117602, Singapore \\ ${ }^{5}$ Singapore Institute of Manufacturing Technology, A*STAR, Singapore 638075, Singapore \\ ${ }^{6}$ Department of Physics, Department of Electrical and Electronics Engineering, UNAM, Bilkent University, \\ Bilkent, Ankara 06800, Turkey \\ ${ }^{7}$ Department of Applied Physics, College of Science and Tianjin Key Laboratory of Low-Dimensional Func- \\ tional Material Physics and Fabrication Technology, Tianjin University, Tianjin 300072, China
}

(Received 24 April 2011; accepted 14 June 2011; published online 15 July 2011)

\begin{abstract}
Transparent and conductive carbon-based materials are promising for window electrodes in solidstate optoelectronic devices. However, the catalytic activity to redox reaction limits their application as a working electrode in a liquid-type dye-sensitized solar cell (DSSC). In this letter, we propose and demonstrate a transparent carbon nanotubes (CNTs) film as the working electrode in a DSSC containing iodide/triiodide redox couples. This implementation is realized by inhibiting the charge-transfer kinetics at CNT/redox solution interface with an aid of thin titanium oxide film that facilitates the unidirectional flow of electrons in the cell without sacrificing the electrical and optical properties of CNT. (C) 2011 American Institute of Physics. [doi:10.1063/1.3610488]
\end{abstract}

Transparent conducting oxides (TCOs) such as indiumdoped tin oxide and fluorine-doped tin oxide are ubiquitously used as window electrodes in optoelectronic devices. However, there exist major technical issues associated with continuing using TCOs as the window electrodes due to their inherent limitations. $^{1-5}$ A recent success in the fabrication of optically transparent and electrically conducting thin film from carbonbased materials using carbon nanotubes (CNTs) and grahene has attracted significant attention. ${ }^{6,7}$ In comparison to traditional TCOs, these carbon-based materials may allow for substantially reduced costs because of the abundant material source and potentially scalable fabrication from solution process. ${ }^{8}$ They are mechanically strong and flexible as well as chemically stable. ${ }^{9,10}$ More interestingly, they remain transparent in the near infra-red region, in contrast to TCO ${ }^{5,6}$ As such, CNT and graphene have been demonstrated as the window electrode in a wide range of solid-state applications. ${ }^{11-15}$ However, it has not been possible to integrate carbon-based materials as a working electrode in liquid-type dye-sensitized solar cell (DSSC) to date because of their well-known catalytic property to redox reaction. Thus, it has been appropriate to use them as a counter electrode in DSSC to replace expensive Pt. ${ }^{16}$ When they are used as a working electrode, however, their catalytic property allows the collected electrons at the working electrode to recombine with $\mathrm{I}_{3}{ }^{-}$in the electrolyte by the reaction $\mathrm{I}_{3}{ }^{-}+2 \mathrm{e} \rightarrow 3 \mathrm{I}^{-}$, at the electrolyte/working electrode interface. Hence, despite the fact that CNT and graphene have

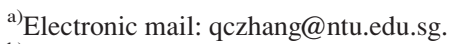

b) Author to whom correspondence should be addressed. Electronic mail: exwsun@ntu.edu.sg.
}

similar work functions (4.7-4.9 eV and $\sim 4.6 \mathrm{eV}$, respectively) to that of conventional TCOs, no liquid-type DSSC with a carbon-based working electrode could be realized so far.

To circumvent this problem, we proposed and employed a facile method for surface modification with thin oxide layer, suppressing the recombination of electrons with $\mathrm{I}_{3}{ }^{-}$, as illustrated in Fig. 1, while maintaining the electrical and optical properties of the working electrode made of CNTs. Although this approach would solve the problem, the prerequisites for an ideal oxide used in the modification limits the choice of available materials. For example, a sol-gel processed $\mathrm{ZnO}$ film has been proven as a highly transparent, electron-transporting layer in an organic solar cell. ${ }^{17}$ However, $\mathrm{ZnO}$ is not compatible with acid-containing anatase paste and dye solution. Alternatively, a compact $\mathrm{TiO}_{2}$ layer by spray-pyrolysis is able to withstand the acid, ${ }^{18}$ but heating/ pre-heating the substrate at high temperature during film deposition oxidizes the CNTs. Thus, herein, we have modified the CNT film with sol-gel-processed titanium sub-oxide $\left(\mathrm{TiO}_{x}\right)$ at low temperature $\left(150^{\circ} \mathrm{C}\right)$. By modifying CNTs with $\mathrm{TiO}_{x}$, we demonstrated that the efficiency can be tremendously improved.

Our transparent, conductive CNT films were produced by air-gun spray method from the solution containing 0.2 $\mathrm{mg} / \mathrm{ml}$ single-wall CNT dispersion (Carbon solution, Inc.) and 0.5 wt. $\%$ sodium dodecylbenzene sulfonate surfactant in water. ${ }^{19}$ Prior to spraying, the mixture was probesonicated at $120 \mathrm{~W}$ to make a homogenous mixture. After the film deposition, the surfactant was removed by immersion in distilled water for $24 \mathrm{~h}$. Some CNT films were immersed in 98 wt. \% sulfuric acid for 30 min to yield doped 
(a)

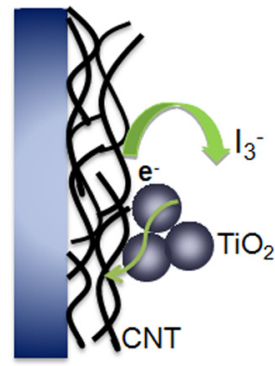

(b)

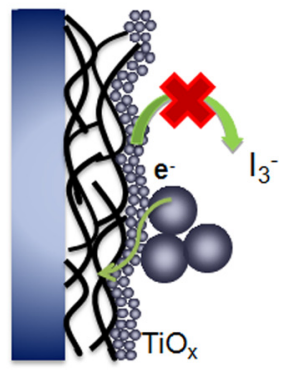

(c)

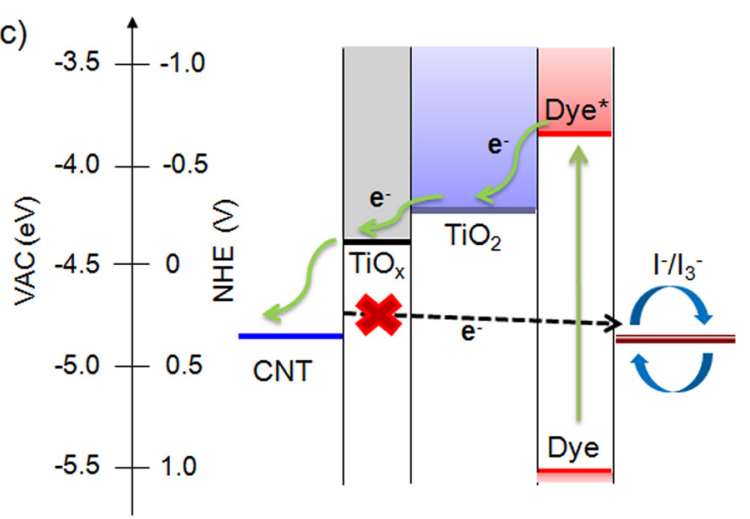

FIG. 1. (Color online) Schematic of (a) recombination of electrons with $\mathrm{I}_{3}{ }^{-}$ at the CNT/electrolyte interface in the case of bare CNT electrode, (b) inhibiting the charge-transfer kinetics at the interface by using a thin $\mathrm{TiO}_{x}$ layer, (c) unidirectional flow of electrons in the liquid-type DSSC with the $\mathrm{TiO}_{x}$-modified-CNT working electrode, showing the energetics of the individual components used in the cell.

CNT films. A number of well-entangled and interconnected CNTs with a general diameter of $10-25 \mathrm{~nm}$ were observed in the resultant film under scanning electron microscopy (SEM) (Fig. 2(a)). The relationship between the sheet resistance and the optical transmittance of the doped and undoped CNTs at the optical wavelength of $600 \mathrm{~nm}$ is shown in Fig. 2(b). Generally, the doped CNT film yields higher transmittance compared to the undoped one at the same sheet resistance. The optimum combination of sheet resistance and transmittance occurs for
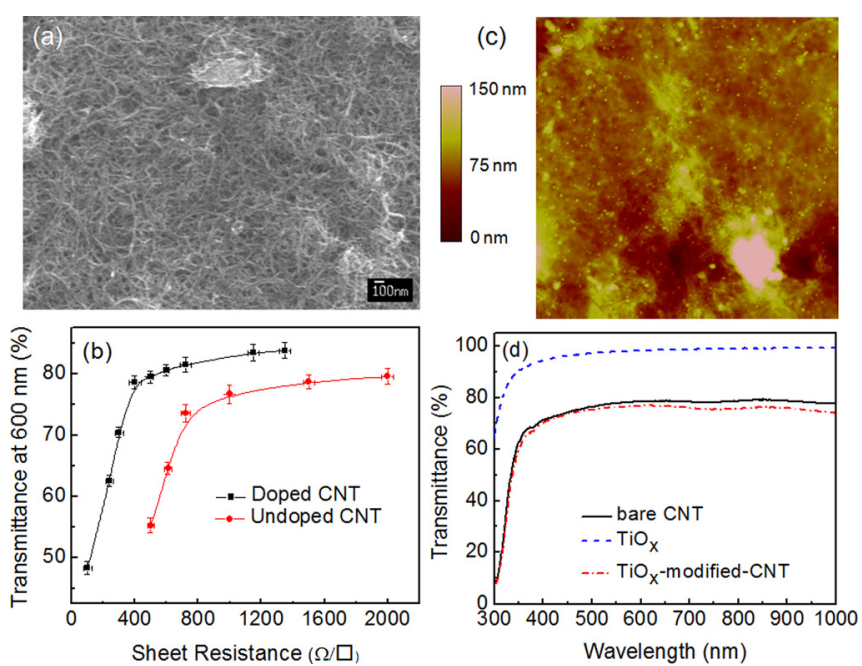

FIG. 2. (Color online) (a) SEM image of a typical CNT film deposited by air-gun spray. (b) The sheet resistance vs. optical transmittance of the doped and undoped CNT film. (c) AFM image of $\mathrm{TiO}_{x}$ coated CNT film $\left(8.0 \times 8.0 \mu \mathrm{m}^{2}\right)$. (d) Typical optical transmittance spectra of the bare CNT, $\mathrm{TiO}_{x}$, and $\mathrm{TiO}_{x}$-modified-CNT films.
400-450 $\Omega / \square$ while the corresponding transmittance is around 75\%-78\%. Hence, the doped CNT film with a sheet resistance $400 \pm 20 \Omega$ was chosen for our device fabrication.

$\mathrm{TiO}_{x}$ sol-gel was prepared by refluxing $1 \mathrm{ml}$ of titanium (IV) isopropoxide, $5 \mathrm{ml}$ of 2-methoxyethanol, and $0.5 \mathrm{ml}$ of ethanolamine in a three-necked flask under argon environment at $80^{\circ} \mathrm{C}$ for $2 \mathrm{~h}$ and $120^{\circ} \mathrm{C}$ for $1 \mathrm{~h}^{20}$ The prepared sol-gel was spin-coated onto the CNT film at $3000 \mathrm{rpm}$. The thickness of the film was controlled by diluting with 2-methoxyethanol. Subsequently, the samples were heated at $150^{\circ} \mathrm{C}$ for $1 \mathrm{~h}$ in air. The precursor was hydrolyzed and converted to $\mathrm{TiO}_{x}$ during heating in air. The elemental composition of $\mathrm{Ti}$ and $\mathrm{O}$, cross-checked by $\mathrm{X}$-ray photoelectron spectroscopy, is $41.9 \%$ and $56.6 \%$, respectively. Hence, the film is considered as titanium sub-oxide, rather than titanium dioxide. As seen from atomic force microscopy (AFM) image (Fig. 2(c)), the resulting $\mathrm{TiO}_{x}$ film is composed of myriad nano-sized colloids, completely covering the underlying CNT bundles. The modification of CNT film with ultra-thin $\mathrm{TiO}_{x}$ layer slightly affects the sheet resistance of the overall electrode. The sheet resistance of $\mathrm{TiO}_{x}$-modified-CNT film increases only to $550 \pm 20 \Omega / \square$ with a 10 -nm-thick $\mathrm{TiO}_{x}$ film from $400 \pm 20 \Omega / \square$ for the bare CNTs. More interestingly, $\mathrm{TiO}_{x}$ film is highly transparent in visible region as well as the near infra-red range and, hence, the transmittance of bare and modified CNT films is nearly the same (Fig. 2(d)).

To demonstrate that $\mathrm{TiO}_{x}$-modified-CNT films serve as potential window electrodes for liquid-type DSSCs, we fabricated a DSSC using porous $\mathrm{TiO}_{2}$ as the wide-bandgap semiconductor, cis-diisothiocyanato-bis(2,2'-bipyridyl-4' dicarboxylato)ruthenium(II) bis(tetrabutylammonium) (Solarnonix) as the sensitizer, $\mathrm{I}^{-} / \mathrm{I}_{3}{ }^{-}$solution as the electrolyte, $\mathrm{Pt}$ as the counter electrode, and $\mathrm{TiO}_{x}$-modified-CNT/bare CNT as the working electrode. The $J-V$ characteristics of the cells with the bare CNT electrode and the $\mathrm{TiO}_{x}$-modified-CNT electrode $\left(\mathrm{TiO}_{x} \sim 10 \mathrm{~nm}\right)$ under illumination of AM1.5G simulated solar light $\left(100 \mathrm{~mW} / \mathrm{cm}^{2}\right)$ are shown in Fig. 3. The short-circuit current density $\left(J_{s c}\right)$, open-circuit voltage $\left(V_{o c}\right)$, fill factor (FF), and power conversion efficiency (PCE) of the cell using the bare CNT electrode are $0.281 \mathrm{~mA} / \mathrm{cm}^{2}, 0.057$ $\mathrm{V}, 23 \%$, and nearly $0 \%$, respectively, and the cell is therefore almost nonfunctional. By modifying CNTs with $\mathrm{TiO}_{x}$,

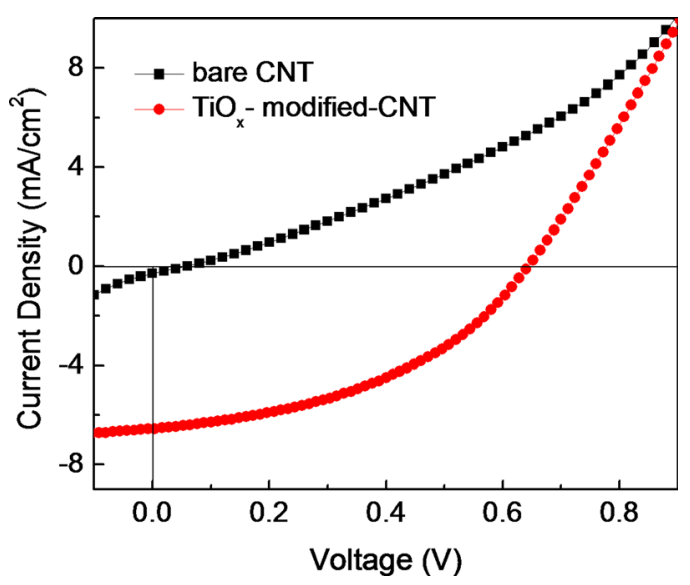

FIG. 3. (Color online) $J-V$ characteristics of liquid-type DSSC with the bare CNT electrode and the $\mathrm{TiO}_{x}$-modified-CNT electrode under simulated solar irradiation of AM1.5G (1 sun). 

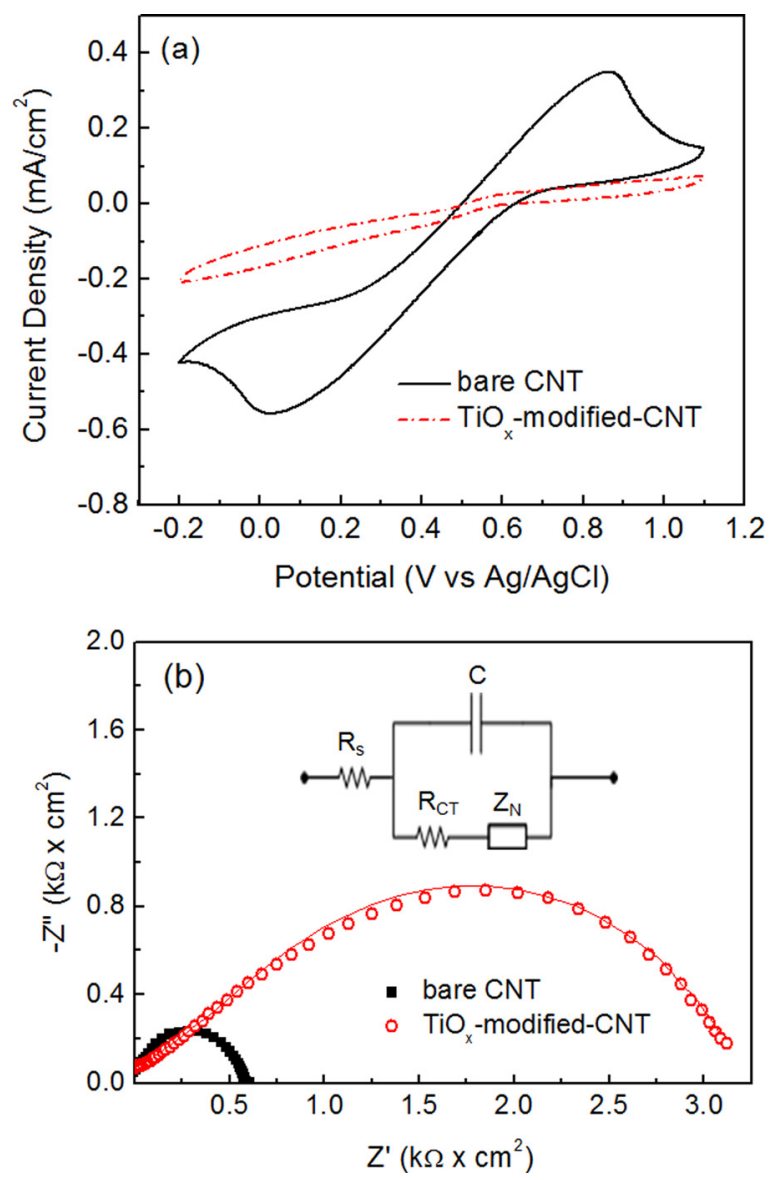

FIG. 4. (Color online) (a) Cyclic voltammograms of the bare CNT and $\mathrm{TiO}_{x}$-modified-CNT electrodes at a scan rate of $10 \mathrm{mV} / \mathrm{s}$. (b) The Nyquist plots of the electrodes at a bias of $300 \mathrm{mV}$. The frequency range was from 0.1 to $100 \mathrm{kHz}$. Inset is the equivalent circuit used in fitting data. Pt plate and $\mathrm{Ag} / \mathrm{AgCl}$ were used as the counter and reference electrodes, respectively, in all electrochemical tests.

however, the PCE of the cell significantly improves to $1.8 \%$ with $J_{s c}$ of $6.547 \mathrm{~mA} / \mathrm{cm}^{2}, V_{o c}$ of $0.644 \mathrm{~V}$, and FF of $43 \%$.

To further understand the role of $\mathrm{TiO}_{x}$ in the CNTelectrode-based DSSC, we studied the electron-transfer properties of the electrodes using cyclic voltammetry (CV). Fig. 4(a) shows the $\mathrm{CV}$ response of the electrodes in $0.1 \mathrm{M} \mathrm{KCl}$ solution containing $5.0 \mathrm{mM} \mathrm{K}{ }_{3} \mathrm{Fe}(\mathrm{CN})_{6}$ at a scan rate of 10 $\mathrm{mV} / \mathrm{s}$. The bare CNT electrode shows a quasi-reversible characteristic with a cathodic peak of $0.56 \mathrm{~mA} / \mathrm{cm}^{2}$ at a reduction potential $0.026 \mathrm{~V}$ and an anodic peak of $0.35 \mathrm{~mA} / \mathrm{cm}^{2}$ at an oxidation potential $0.86 \mathrm{~V}$, suggesting that there is electron-transfer between the CNTs and the redox system. In contrast, neither cathodic nor anodic peak was observed in $\mathrm{CV}$ response of $\mathrm{TiO}_{x}$-modified-CNT electrode, indicating that the electron transfer between the CNTs and the redox species is blocked by $\mathrm{TiO}_{x}$. We also conducted electrochemical impedance spectroscopy to evaluate charge-transfer resistance $\left(\mathrm{R}_{\mathrm{CT}}\right)$ at the electrode/electrolyte interface. Fig. 4(b) shows the Nyquist plots of a three-electrode system in an electrolyte containing $0.05 \mathrm{M} \mathrm{I}_{2}$ and $0.5 \mathrm{M} \mathrm{LiI}$ in aqueous solution. The plots were fitted with the equivalent circuit model (inset Fig. 4(b)). $\mathrm{R}_{\mathrm{CT}}$ indicates the electron transfer resistance between the electrode and electrolyte. The Nernst diffu- sion impedance $\left(\mathrm{Z}_{\mathrm{N}}\right)$ describes the diffusion of $\mathrm{I}_{3}{ }^{-}$in electrolyte while $R_{s}$ stems from the ohmic resistance of the electrolyte and electrodes. ${ }^{21,22}$ From the fitted data, $\mathrm{R}_{\mathrm{CT}}$ of $\mathrm{TiO}_{x}$-modified-CNT electrode was found to be $2.513 \mathrm{k} \Omega \cdot \mathrm{cm}^{2}$ while that of bare CNT electrode was only $311.4 \Omega \cdot \mathrm{cm}^{2}$. Because $\mathrm{R}_{\mathrm{CT}}$ varies inversely with the $\mathrm{I}_{3}{ }^{-}$reduction activity of the electrode, the larger $\mathrm{R}_{\mathrm{CT}}$ of $\mathrm{TiO}_{x}$-modified-CNT film suggests that the reduction of $\mathrm{I}_{3}{ }^{-}$at the CNT/electrolyte interface is largely suppressed by $\mathrm{TiO}_{x}$.

In conclusion, we proposed and demonstrated the feasibility of carbon-based transparent, conductive film made of CNTs as the working electrode in a DSSC containing redox solution, enabled by surface modification of CNTs using $\mathrm{TiO}_{x}$, which serves as a retardation medium to electrontransfer kinetics at the CNT/electrolyte interface without degrading the electrical and optical properties of CNTs. As a result, the power conversion efficiency of $1.8 \%$ has been realized. With further optimization in the sheet resistance and transmittance, carbon-based window electrodes could offer a viable low-cost alternative to conventional TCOs in both solid-state and liquid-type optoelectronic devices.

This work was supported by Academic Research Fund (RGM 44/06) of Nanyang Technological University and the National Research Foundation (Grant Nos. NRF-RF-2009-09 and NRF-CRP-4-2008-04).

${ }^{1}$ S. R. Forrest, Nature 428, 911 (2004).

${ }^{2}$ T. Minami, Thin Solid Films 516, 1314 (2008).

${ }^{3}$ A. R. Schlatmann, D. W. Floet, A. Hilberer, F. Garten, P. J. M. Smulders, T. M. Klapwijk, and G. Hadziioannou, Appl. Phys. Lett. 69, 1764 (1996).

${ }^{4}$ Z. Chen, B. Cotterell, W. Wang, E. Guenther, and S.-J. Chua, Thin Solid Films 394, 201 (2001).

${ }^{5}$ L. Hu, D. S. Hecht, and G. Gruner, Appl. Phys. Lett. 94, 081103 (2009).

${ }^{6}$ Z. Wu, Z. Chen, X. Du, J. M. Logan, J. Sippel, M. Nikolou, K. Kamaras, J. R. Reynolds, D. B. Tanner, A. F. Hebard, and A. G. Rinzler, Science 305, 1273 (2004).

${ }^{7}$ X. Li, Y. Zhu, W. Cai, M. Borysiak, B. Han, D. Chen, R. D. Piner, L. Colombo, and R. S. Ruoff, Nano Lett. 9, 4359 (2009).

${ }^{8}$ B. Dan, G. C. Irvin, and M. Pasquali, ACS Nano 3, 835 (2009).

${ }^{9}$ E. Frackowiak and F. Béguin, Carbon 39, 937 (2001).

${ }^{10} \mathrm{~B}$. Yakobson and P. Avouris, in Carbon Nanotubes, edited by M. Dresselhaus, G. Dresselhaus, and P. Avouris (Springer, Berlin, 2001), Vol. 80, p. 287.

${ }^{11}$ Q. Cao, Z.-T. Zhu, M. G. Lemaitre, M.-G. Xia, M. Shim, and J. A. Rogers, Appl. Phys. Lett. 88, 113511 (2006).

${ }^{12}$ J. Wu, M. Agrawal, H. C. A. Becerril, Z. Bao, Z. Liu, Y. Chen, and P. Peumans, ACS Nano 4, 43 (2009).

${ }^{13}$ M. W. Rowell, M. A. Topinka, M. D. McGehee, H.-J. Prall, G. Dennler, N. S. Sariciftci, L. Hu, and G. Gruner, Appl. Phys. Lett. 88, 233506 (2006).

${ }^{14}$ X. Wang, L. Zhi, and K. Mullen, Nano Lett. 8, 323 (2007).

${ }^{15}$ J. van de Lagemaat, T. M. Barnes, G. Rumbles, S. E. Shaheen, T. J. Coutts, C. Weeks, I. Levitsky, J. Peltola, and P. Glatkowski, Appl. Phys. Lett. 88, 233503 (2006).

${ }^{16}$ H. Zhu, H. Zeng, V. Subramanian, C. Masarapu, K.-H. Hung, and B. Wei, Nanotechnology 19, 465204 (2008).

${ }^{17}$ A. K. K. Kyaw, X. W. Sun, C. Y. Jiang, G. Q. Lo, D. W. Zhao, and D. L. Kwong, Appl. Phys. Lett. 93, 221107 (2008).

${ }^{18}$ U. Bach, D. Lupo, P. Comte, J. E. Moser, F. Weissortel, J. Salbeck, H. Spreitzer, and M. Gratzel, Nature 395, 583 (1998).

${ }^{19}$ H.-Z. Geng, K. K. Kim, K. P. So, Y. S. Lee, Y. Chang, and Y. H. Lee, J. Am. Chem. Soc. 129, 7758 (2007).

${ }^{20}$ K. Lee, J. Y. Kim, S. H. Park, S. H. Kim, S. Cho, and A. J. Heeger, Adv. Mater. 19, 2445 (2007).

${ }^{21}$ Q. Wang, J.-E. Moser, and M. Grätzel, J. Phys. Chem. B 109, 14945 (2005).

${ }^{22}$ A. Hauch and A. Georg, Electrochim. Acta 46, 3457 (2001). 